\title{
Public sector funding in the UK
}

\section{MRC spearheads initiatives aimed at UK biotechnology startups.}

\author{
David A. A. Owen
}

Despite the creativity in its science base, the biotechnology industry started more slowly in the United Kingdom than in the United States-possibly because there was such strength and creativity in the UK pharmaceutical industry and consequently less stimulus for alternative ways to exploit scientific excellence. More recently, and perhaps making up for lost time, the UK biotechnology sector has grown considerably. It is now second only to the United States in its quality and scale, although competition is gathering in continental Europe, particularly in France and Germany. Both the public and private sectors have developed widespread support mechanisms to foster the creation of new biotechnology companies and to sustain these companies once formed.

\section{Funding from research councils and charities}

In the United Kingdom, research within the science base that underpins the biotechnology industry is supported primarily by the Medical Research Council (MRC; London) and the research charities, but also by the Biotechnology and Biological Sciences Research Council (BBSRC), the Engineering and Physical Sciences Research Council (PSRC), and the Natural Environment Research Council (NERC), all based in Swindon. Each of these has its own mechanisms of support, but the MRC serves as a good example of the type of initiatives that are currently under way.

The MRC funds research both in its own laboratories (MRC Institutes and Units), and in response to successful grant applications from universities. It owns and manages the intellectual property/property rights from its own laboratories and has a dedicated technology transfer group (TTG) in its head office to drive these activities.

In recent years, the MRC files more than 30 new patent applications and completes 15-25 licensing agreements annually. In addition to licensing, the TTG works closely with MRC researchers in biotechnology company formation and has participated comprehensively (preparation of business plans,

David A. A. Owen is director, Industrial Collaboration \& Licensing, Medical Research Council, 20 Park Crescent, London W1N 4AL (David.Owen@headoffice.mrc.ac.uk).
More recently, and perhaps making up for lost time, the UK biotechnology sector has grown considerably. It is now second only to the United States in its quality and scale, although competition is gathering in Europe.

raising finance, and recruitment of management) to form such companies as Cambridge Antibody Technology (Cambridge), Therexsys (Keele), Prolifix (Oxfordshire), RiboTargets (Cambridge), Cambridge Genetics (Cambridge), and other earlierstage companies. Currently, about 20 biotechnology companies have been formed to exploit technology from MRC laboratories or have restructured their goals to exploit technology originating in the MRC.

In addition to the TTG, MRC has established two laboratory-based technology transfer functions-the MRC Collaborative Centres. The first center was established in Mill Hill in the mid-1980s, adjacent to the National Institute for Medical Research. The second center, in Edinburgh, was formally opened in autumn 1997. The Mill Hill center has undertaken successful technology transfer activities with more than 30 companies and has provided management expertise and other infrastructure support to MRC "spinoff" companies.

The most recent MRC biotechnology development is the establishment of the MRC's own investment fund, UK Medical Ventures Fund. This fund has raised more than $£ 38$ (\$60) million from private sources to stimulate further biotechnology company spinouts, based primarily on technology originating in MRC laboratories. The CEO of UK Medical Ventures Management is Stephen Reeders.

Elsewhere, the medical research charity sector is a significant source of funding to UK academia and the larger charities have, or are developing, effective exploitation functions. These include the Wellcome Trust (London), led by Graham Fagg, the Cancer Research Campaign Technology (London), led by Sue Foden, and the Imperial Cancer Research
Technology (London), led by John Wall.

\section{Funding from government sources}

Some years ago, UK biotechnology received a great boost through the creation of a chemicals and biotechnology division within the Department of Trade and Industry (DTI; London). The biotechnology section, headed by Elizabeth Baker, has worked effectively with the Treasury to establish imaginative schemes to foster UK biotechnology and aid bioentrepreneurs. Among these initiatives are changes to tax law to encourage "business angels" to invest in startup companies across all sectors of industry, including biotechnology. For companies at their founding stage, a biotechnology finance advisory service and a biotechnology mentoring and incubator challenge have also been established.

In March, the chancellor announced that the 1998 budget will provide further support for small businesses by cutting taxes, cutting the costs of investing, cutting the burden of red tape, and increasing the rewards for doing well. He also announced plans for a new $£ 50$ (\$84) million venture capital fund open to all UK universities - the "University Challenge."

For early-stage, but more established biotechnology companies, the DTI provides support through its SMART scheme, in which the DTI funds, alongside company money, to support agreed R\&D programs. DTI, other government departments, and the research councils participate in LINK programs, intended to foster joint working between one or more academic laboratories and one, or preferably more, companies. The key principle is that the participating companies provide not less than $50 \%$ of the funding, in cash or kind, with the balance from public purses. These schemes are available to all companies, large or small, that have R\&D or manufacturing facilities in the UK. DTI funding to LINK is targeted particularly at small companies.

\section{Conclusions}

The long tradition of academic excellence in the UK is finally being mirrored by a strong and growing biotechnology industry. Specific initiatives such as the MRC's UK Medical Ventures Fund, and recently announced government measures, coupled with a growing spirit of entrepreneurship, should provide further impetus to growth of its biotechnology sector. 